\title{
STUDI LIVING QUR'AN TERHADAP AMALAN IBU HAMIL DI KECAMATAN BERUNTUNG BARU KABUPATEN BANJAR ${ }^{1}$
}

\author{
Isnawati \\ Jurusan Tafsir Hadis Fakultas Ushuluddin dan Humaniora \\ IAIN Antasari Banjarmasin \\ Diterima tanggal 5 Oktober 2015/ Disetujui tanggal 19 September 2015
}

\begin{abstract}
Along with the times, study the Koran and Hadith experiencing developments study area, from the study of texts to the socio-cultural studies, which is then referred to as "Iiving Koran" and "living tradition". In addition, living study the Koran that not only the existence of textual, but a social phenomenon that was born linked to the presence of the Koran in a specific geographic region and specific future anyway. However, the phenomenon appears not always directly proportional to what is supposed to be practiced and in amalkan. Seeing this phenomenon the author tries to do more research about reading (practice) of the Koran in public District of Lucky New Banjar Regency, the authors wanted to uncover the sura and verse what is used as a bidder, healer or medicine that mamampu cure physically and mental reserved for pregnant women. Any problems with the formulation of sura and verse of the Koran that used pregnant women, and then what are the factors that affect pregnant women mengamlkan suras and verses of the Koran in the District of New Lucky Banjar district.
\end{abstract}

Kata kunci: Living Qur'an, Amalan, dan ibu hamil.

\section{Pendahuluan}

Agama Islam mengandung jalan hidup manusia yang paling sempurna dan berisi ajaran yang membimbing umat manusia menuju kebahagiaan dan kesejahteraan. Al-Quran juga mengajak memikirkan penciptaan manusia sendiri dan rahasia-rahasia yang terdapat dalam dirinya. Ayat-ayat al-Quran mengarahkan manusia dengan tanda-tanda kekuasaan Allah, ayat al-Quran tiada hentinya menaburkan mutiara-mutiara ilmu dan pengetahuan kepada seluruh dunia. Dialah al-Quran mukjizat yang kekal dengan kekalnya manusia di atas permukaan bumi dan menyingkap ufuk-ufuk ilmu dan pengetahuan kepada manusia disetiap saat.

Ditengah-tengah lembaran al-Quran terdapat isyarat-isyarat ilmiah yang banyak memuat hakikat penciptaan manusia, alam semesta, lautan, gunung-gunung, hakikat kedokteran dan hakikat segala ilmu pengetahuan yang telah mendahului ilmu pengetahuan modern lebih dari lima belas abad silam. ${ }^{2}$ Al-Quran merupakan mukjizat yang terbesar diantara mukjizat yang pernah Allah Swt. berikan kepada Nabi-Nya. Kualitas kebenarannya bersifat ilmiah yang tidak dapat dilakukan oleh siapapun sampai hari kiamat nanti. ${ }^{3}$ Sebagaimana firman Allah Swt. dalam Q.S. al-Isrâ'/17: 88 .

\footnotetext{
${ }^{1}$ Artikel merupakan

${ }^{2}$ Ahsin Sako Muhammad, Inseklopedi Kemukjizatan Ilmiah dalam Al-Quran dan Sunnah, (Jakarta: Kharisma Ilmu, 2010), cet. 2,7 .

${ }^{3}$ Tim Perumus Fakultas UMJ Jakarta, Al-Islam dan Iptek (Jakarta: PT. Raja Grafindo Persada, 1998), 3.
} 


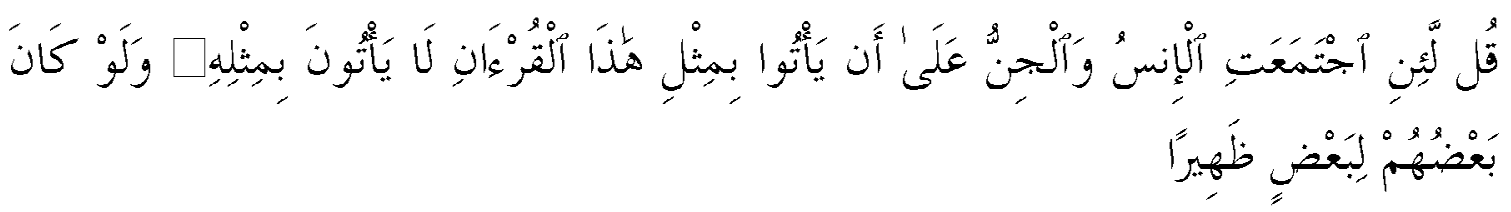

Al-Quran diturunkan oleh Allah Swt. kepada manusia untuk menjadi petunjuk dan menjadi pemisah antara yang hak dan yang batil. ${ }^{4}$ Sesuai dengan firman-Nya dalam Q.S. Al-Baqarah/ 02: 185.

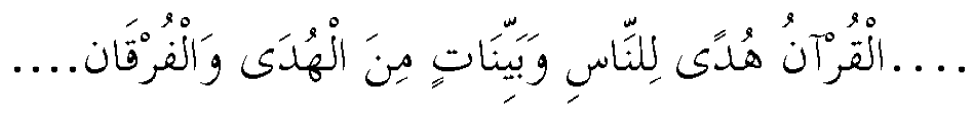

Mengkaji al-Quran, sampai detik ini, masih menjadi urutan terpenting dan pertama dalam upaya mempelajari agama Islam. Tentunya, model pengkajiannya pun sangat berperan di dalam upaya mendapatkan hasil dan tujuan yang optimal.

Seiring perkembangan zaman, kajian mengenai al-Quran dan al-Hadis mengalami pengembangan wilayah kajian. Dari kajian teks kepada kajian sosial-budaya, yang menjadikan masyarakat agama sebagai objeknya. Kajian ini sering disebut dengan istilah "living Qur'an" dan "living Hadis". Secara sederhana, "living Qur'an” dapat dimaknai sebagai gejala yang nampak di masyarakat berupa pola-pola perilaku maupun respons sebagai pemaknaan terhadap nilai-nilai Quran. ${ }^{5}$

M. Mansur berpendapat bahwa the living Qur'an sebenarnya bermula dari fenomena Qur'an in Everyday Life, yang tidak lain adalah "makna dan fungsi al-Quran yang riil difahami dan dialami masyarakat Muslim"6 artinya praktek memfungsikan al-Quran dalam kehidupan praktis, diluar kondisi tekstualnya. Sedangkan Muhammad Yusuf menjelaskan bahwa respon sosial (realitas) terhadap al-Quran dapat dikatakan Living Qur'an, baik itu al-Quran dilihat masyarakat dari ilmu (science) dalam wilayah profane (tidak keramat) di satu sisi dan sebagai buku petunjuk (buda) yang bernilai sakral (sacred value) di sisi lain. ${ }^{7}$

Selain itu, studi mengenai living Qur'an juga merupakan studi al-Quran yang tidak hanya bertumpu pada eksistensi tekstualnya, melainkan tentang fenomena sosial yang lahir terkait dengan kehadiran al-Quran dalam wilayah geografi tertentu dan mungkin masa tertentu pula.

Beberapa pendapat di atas, tidak tampak adanya perbedaan dengan pendapat Abdul Mustaqim. Dalam tulisannya menyatakan bahwa kajian living al-Qur'an mempunyai beberapa arti penting. Menurutnya, terdapat tiga arti penting yang di utarakannya. Pertama, memberikan kontribusi yang signifikan bagi pengembangan wilayah objek kajian al-Quran, dimana tafsir bisa bermakna sebagai respons masyarakat yang diinspirasi oleh kehadiran al-Quran. Kedua, kepentingan dakwah dan pemberdayaan masyarakat, sehingga masyarakat lebih maksimal dan tepat dalam mengapresiasi al-Quran. Ketiga, memberi paradigma baru bagi pengembangan

${ }^{4}$ M. Quraish Shihab, Tafsir Al-Misbah Vol. 1 (Jakarta: Lentera Hati, 2002), 487.

${ }^{5}$ M. Alfatih Suryadilaga, Living Hadis dalam Kerangka Dasar Keilmuan UIN Sunan Kalijaga, Http:// ejournal.unp.ac.id/index.php/pnfi/article/download/1516/pdf, diakses tanggal 02 November 2014.

${ }^{6}$ Muhammad Mansur, Dkk, Living Qur'an dalam Litasan Sejarab Studi Al-Qur'an, dalam Metodologi Penelitian Living Qur'an dan Hadis, Syahiron Syamsuddin (Yogyakarta: TH Press, 2007), cet. 1, 5.

${ }^{7}$ Muhammad Yusuf, Pedekatan Sosiologi dalam Penelitian Living Qur'an, dalam Metodologi Penelitian Living Qur'an dan Hadis, Syahiron Syamsuddin, 36-37. 
kajian al-Quran kontemporer, sehingga studi al-Quran tidak hanya terkutat pada wilayah kajian teks. $^{8}$

Sudah barang tentu, masyarakat Islam semestinya berprilaku sesuai dengan ajaran-ajaran al-Quran dan Hadis. Namun fenomena yang muncul tidak selalu berbanding lurus dengan apa yang semestinya dipraktekkan dan diamalkan. Kajian living Quran semakin menarik seiring dengan meningkatnya kesadaran masyarakat Islam terhadap ajaran agamanya. Kegiatan-kegiatan keagamaan, baik di tempat-tempat tertentu seperti mesjid maupun di media cetak dan elektronik lainnya.

Perlu dikemukakan definisi operasional atau penjelasan dan batasan judul "Studi Living Qur'an terhadap Amalan Ibu Hamil di Kecamatan Beruntung Baru Kabupaten Banjar". sebagai berikut:

1. Studi adalah pelajaran, penggunaan waktu untuk memperoleh ilmu pengetahuan atau penyelidikan. ${ }^{9}$

2. Living adalah mata pencarian, orang yang hidup di alam fana, yang hidup. ${ }^{10}$

3. Qur'an adalah kitab suci umat Islam

Dalam makna tersendiri living Qur'an adalah kajian atau penelitian ilmiah tentang berbagai peristiwa sosial terkait dengan kehadiran al-Quran atau keberadaan al-Quran disebuah komunitas Muslim tertentu. ${ }^{11}$

4. Amalan

Berasal dari kata amal yang berarti perbuatan, usaha nyata ${ }^{12}$ yang dimaksud dalam penelitian ini adalah orang yang membaca surah dan ayat al-Quran secara rutin di masa kehamilan. Surah dalam Kamus Umum Bahasa Indonesia berarti bagian atau bab dalam kitab alQuran sedangkan ayat ialah susunan kata dan kalimat al-Quran yang membentuk makna yang sempurna. ${ }^{13}$ Secara etimologi kata ayat adalah berasal dari bahasa Arab yang berarti tanda, mukjizat, sesuatu yang ajaib, atau beberapa kalimat yang merupakan kesatuan maksud sebagai bagian dari dalam kitab al-Quran. ${ }^{14}$

Jadi amalan yang dimaksud dalam penelitian ini adalah pengamalan (pembacaan) surah dan ayat al-Quran yang dilakukan ibu hamil secara rutin dan terus menerus dari awal kehamilan sampai dengan proses melahirkan.

\section{Metode}

Penelitian ini termasuk penelitian lapangan (field research) dengan lokasi di Kecamatan Beruntung Baru Kabupaten Banjar. Menggunakan metodologi penelitian kualitatif. Dalam

\footnotetext{
${ }^{8}$ Abdul Mustaqim, Living Qur'an dalam Litasan Sejarah Studi Al-Qur'an, dalam Metodologi Penelitian Living Qur'an dan Hadis,... 68-70.

${ }^{9}$ Kamus Umum Bahasa Indonesia, (Jakarta: Pusat Balai Bahasa Indonesia, 2010), cet. 7, 1146.

${ }^{10}$ John Echols dan Hassan Shadily, Kamus Inggris Indonesia (Jakarta: 1976), 362.

${ }^{11}$ M. Mansur, 'Living Qur'an dalam Litasan Sejarah Studi Al-Qur'an", dalam Metodologi Penelitian Living Qur'an dan Hadis, Syahiron Syamsuddin (Yogyakarta, 2007), cet. 1, 8.

${ }^{12}$ Pius A Partanto dan M. Dahlan al Barry,Kamus Ilmiah Populer (Surabaya: Arloka, 1994), 25.

${ }^{13}$ Nur Kholis, Pengantar Studi Al-Qur'an dan Al-Hadist (Yogjakarta: Teras, 2008), cet. 1, 39.

${ }^{14}$ W.J.S. Poerwadarminta, Kamus Umum Bahasa Indonesia (Jakarta: Balai Pustaka, 2010), cet. 7, 72.
} 
penelitian ini mengunakan beberapa metode yang digunakan dalam metode pengumpulan data yang digunakan adalah observasi, intervie (wawancara), dokumentasi, dan analisis. Metode dalam pengumpulan data. Pertama Obsevasi yang lansung terjun kelapangan. Kedua intervie (wawancara) dengan beberapa masyarakat yang menjadi informan mengenai surah dan ayat al-Quran yang digunakan ibu hamil di Kecamatan Beruntung Baru Kabupaten Banjar. Ketiga dokumentasi untuk mendukung data yang diperoleh selama observasi dan interview. Keempat Analisis yang digunakan adalah dengan metode deskriptif.

Karena banyaknya populasi. Maka, menggunakan beberapa sample dengan teknik Random Sampling yakni 15 orang (ibu yang pernah hamil) yang diambil dari wilayah Kecamatan Beruntung Baru Kabupaten Banjar. Teknik Random Sampling adalah teknik pengambilan sample seraca teknik acak, dalam Random Sampling semua individu dalam populasi baik secara sendiri-sendiri atau bersama-sama diberi kesempatan yang sama untuk dipilih menjadi anggota sampel. ${ }^{15}$

Setelah dilakukan penelitian dari interview mendalam terhadap lima belas responden ibu hamil yang mempunyai amalan al-Quran di Kecamatan Beruntung Baru Kabupaten Banjar. Maka diperoleh hasil sebagai berikut: hasil penelitian dilapangan menunjukkan, pelaksanaan pembacaan (pengamalan) al-Quran bagi ibu hamil di Kecamatan Beruntung Baru Kabupaten Banjar.

\section{Pembahasan}

Dalam lintas sejarah Islam, bahkan pada era yang sangat dini, praktek memperlakukan alQuran atau unit-unit tertentu dari al-Quran sehingga bermakna dalam kehidupan praksis umat pada dasarnya sudah terjadi ketika Nabi Muhammad Saw. masih hidup. ${ }^{16}$

Berinteraksi dengan al-Quran menghasilkan pemahaman dan penghayatan terhadap ayat al-Quran tertentu secara atomistik. Pemahaman dan penghayatan individual yang diungkapkan dan dikomunikasi secara verbal maupun dalam bentuk tindakan dapat mempengaruhi individu lain, sehingga membentuk kesadaran bersama. Pada taraf tertentu, melahirkan tindakan-tindakan kolektif dan terorganisasi. Pengalaman bergaul dengan al-Quran itu meliputi bermacam-macam bentuk kegiatan, misalnya membaca al-Quran memahami dan menafsirkan al-Quran, berobat dengan al-Quran, mengusir makhluk halus dengan al-Quran menerapkan ayat-ayat al-Quran tertentu dalam kehidupan individual maupun dalam kehidupan sosial. ${ }^{17}$

Al-Quran juga menuntun manusia untuk menjalani segala aspek kehidupan, jauh sebelum ilmu pengetahuan al-Quran telah memberi penjelasan tahapan penciptaan manusia. Rangkaian perjalanan hidup manusia mulai dari kelahiran hingga berakhir pada saat seseorang meninggal dunia. Kehidupan manusia dimulai saat pembuahan, yaitu ketika suatu sel telur bertemu dengan

\footnotetext{
${ }^{15}$ Risno Hadi, Metodologi Resecrch (Yogyakarta: Aadi Otset,1994), 5.

${ }^{16}$ Muhammad Mansur, "Living Qur'an dalam Lintasan Sejarah Studi Al-Qur'an", dalam Metodologi Penelitian Living Qur'an dan Hadis, h. 3, laporan riwayat konon Nabi Saw pernah menyembuhkan penyakit dengan ruquah lewat surah alFatihah, atau menolak sihir dengan surah al-Muja'awwizattain. Kalau praktik semacam ini sudah ada pada zaman Nabi Saw, maka hal ini berarti bahwa al-Qur'an diperlakukan sebagai pemangku fungsi diluar kapasitasnya sebagai teks. Sebab secara sem

${ }^{17}$ Muhammad Chirzin, Mengungkap Pengalaman Muslim Berinteraksi dengan al-Quran, dalam Metodologi Penelitian Living Qur'an dan Hadis,.... 11.
} 
sel sperma. Hal ini terjadi kira-kira dua ratus delapan puluh lima hari sebelum lahir. ${ }^{18}$ Sesuai fitrahnya naluri manusia mempunyai kecenderungan untuk mempunyai keturunan yang sah keabsahan anak turunan yang diakui oleh dirinya sendiri, masyarakat, negara dan kebenaran keyakinan agama Islam memberi jalan untuk itu. ${ }^{19}$ Yaitu dengan berkeluarga secara sah menurut agama maupun negara. Tujuan pernikahan membentuk keluarga bahagia akan makin lengkap kiranya apabila seorang anak sebagai permata hati dalam bahtera rumah tangga. ${ }^{20}$ Kehidupan kelurga bahagia, umumnya ditentukan kehadiran anak-anak, banyak rumah tangga yang kandas karena tidak memiliki anak.

Jika ingin memetik buah yang manis dan unggul, semestinya harus pandai-pandai merawat sejak dini, sejak memilih benihnya atau menyemai dalam kandungan. Begitu pula dalam kehidupan berumah tangga, al-Quran juga menganjurkan selalu berdoa agar dianugrahkan anak yang menjadi mutiara dari istrinya, sebagaimana yang tercantum dalam Q.S. Al-Furqan/ 25: 74 .
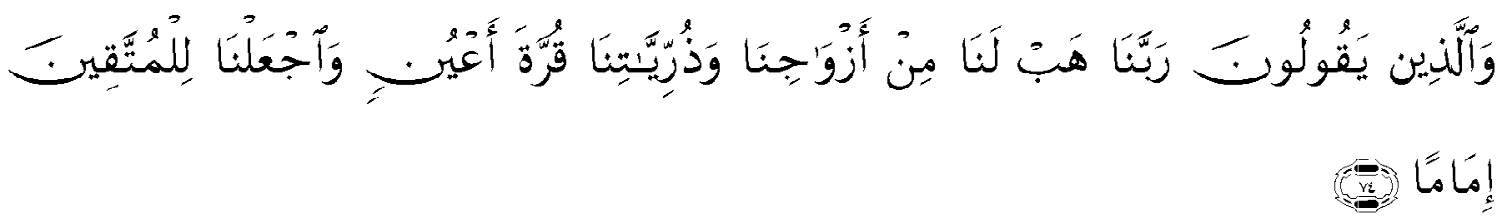

Begitu besarnya peran anak terhadap orang tuanya, maka hendaknya anak dididik sejak dari kandungan. Khusus bagi ibu hamil, maka pada mendidik anak mutlak bagi ibu dibanding bapaknya. Banyak perilaku dan usaha yang dilakukan ibu hamil dalam rangka mendidik dan menjadikan anak yang dikandungnya kelak menjadi anak yang membahagiakan orang tua (Qurrata A'yun) dan menjadi pemimpin yang mampu menjalankan syariat agama dengan baik (Taqwa).

Al-Quran mengukapkan penderitaan ibu hamil dalam Q.S. Luqmân/31:14.

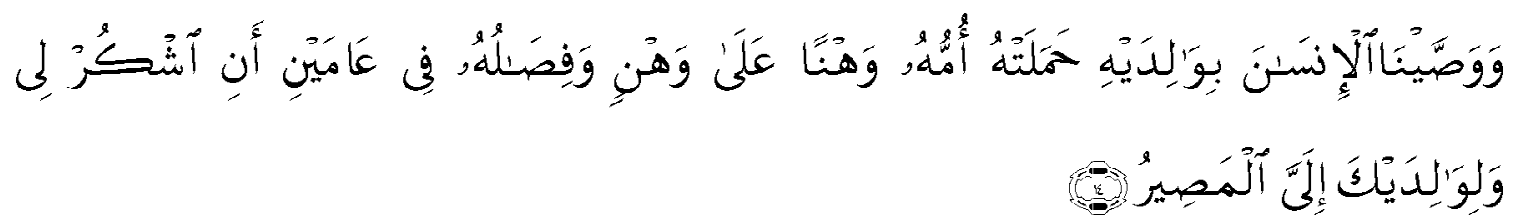

Kebanyakan ibu hamil mengungkapkan bahwa saat hamil mereka mengalami ketakutan di saat hamil dan di saat melahirkan. Mereka banyak yang menjadikan al-Quran sebagai penghilang ketakutan, penawar, penyembuh atau obat kegelisahan, memelihara diri dengan mengamalkan al-Quran dan hadis-hadis Nabi Muhammad Saw. mereka merasa nyaman dan tenang dan yang lebih penting mereka merasakan keselamatan dan kurang kesakitan (penderitaan) serta aman, di saat melahirkan bayi yang dikandungnya.

Surah dan ayat al-Quran yang dijadikan sebagai penawar, penyembuh atau obat yang dapat menyembuhkan penyakit lahir maupun batin khususnya untuk ibu hamil hingga melahirkan. Maka surah dan ayat al-Quranlah sebagai penawarnya. Hal tersebut juga dijelaskan dalam buku al-Qur'an a Short Introduction, Farid Esack menyatakan bahwa al-Qur'an fulfills many of function in

\footnotetext{
${ }^{18}$ Emma Pandi Wirakusumah, Sehat Cara AL-Qura'an dan Hadis (Jakarta: Hikmah, 2010), cet. 1, 3.

${ }^{19}$ Abdul Rahman ghozali, Fiqhi Munakahat (Jakarta: Kencana, 2010), cet. Ke 4, 24.

${ }^{20}$ Novaria AI dan TP Budi, Tips Cerdas Kehamilan (Jakarta: Suka Buku, 2012), cet. Ke 1, 148.
} 
lives of muslims. ${ }^{21} \mathrm{Al}$-Quran mampu memenuhi banyak fungsinya di dalam kehidupan muslim. Al-Quran bisa berfungsi sebagai pengerem tindakan dzalim, penyelamat dari malapetaka. Dari fungsi-fungsi itu, mulai nyatalah bahwa al-Quran benar-benar memberikan makna yang konkrit dalam kehidupan seorang muslim. ${ }^{22}$ Oleh karena itu, hingga kini al-Quran tetap dijadikan pegangan hidup.

Hal hampir serupa juga dikemukakan oleh Abdul Mustaqim dkk. dalam bukunya, Metode Living Qur'an dan Hadis, bahwa al-Quran membawa keberkahan bagi manusia yang mempercayainya. Apabila seorang muslim menghadapi kesulitan hidup, kegoncangan jiwa termasuk stres, depresi, sindrom, bisa disembuhkan dengan kekuatan magis spritual yang ada di dalam ayat-ayat tertentu dengan kekuatan suci dari alam transedensi. ${ }^{23}$

Alfani Daud mengatakan bahwa: sebagian masyarakat Banjar percaya bahwa setiap wanita yang mengetahuinya dirinya sedang hamil harus sadar bahwa ia menghadapi situasi yang berbahaya, karena itu ia harus mempersiapkan diri dan memperhatikan tabu-hamil, bagi wanitawanita tertentu pada umur kehamilan pertama tujuh bulan atau beberapa bulan sesudahnya. ${ }^{24}$ Banyak orang yang mengabaikan hal ini karena terkesan tabu atau bahkan mitos saja melakukan ritual, namun dalam tradisi orang Banjar sendiri memiliki tradisi "bamandi-mandi" untuk menyambut kelahiran bayi dengan berbagai ritual dan pembacaan doa-doa ketika hamil dan ketika melahirkan.

Surah dan ayat al-Quran dijadikan sebagai penawar dan doa-doa. Ayat bisa ditulis dengan tinta, baik dikertas, maupun langsung didalam pembuluh, kemudian teks tersebut dihancurkan di dalam air. ${ }^{25}$

Sudah sewajarnya Muslim mengetahui bahwa Allah Swt. menurunkan al-Quran untuk menjelaskan segala sesuatu menjadikan Rahmat dan kegembiraan bagi Muslim. Keistimewaan al-Quran (I'jaz al-Qur'an) telah menjadikan magnet dan motivasi kuat untuk menjadikan alQuran sebagai pedoman hidup. Di dalam al-Qur'an terdapat ayat-ayat Syifấ yang memilki khasiat sebagai wasilah untuk mendapatkan kesembuhan dari berbagai penyakit. Tentu saja sangat penting untuk diketahui oleh umat Islam. Terlebih dimasa sekarang ini, dimana biaya pengobatan semakin mahal dan keadaan perekonomian umat Islam secara umum masih dibilang sangat memprihatinkan. Maka tentu saja perlu ada alternatif yang dapat digunakan bagi umat Islam yang tengah sakit dan tidak mampu untuk membiayainya.

Berikut ayat-ayat syifa

1. Q.S. At-Taubah/09: 14.

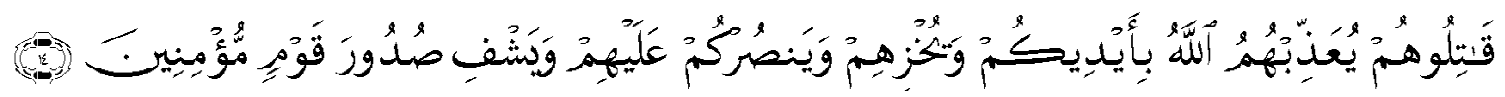

\footnotetext{
${ }^{21}$ Farid Esack, Menghidupkan Al-Qur'an dalam Wacana \& Prilaku, Judul Asli: al-Qur'an a Short Introduction, Penerjemah: Norma Arbi’â Juli Setiawan (Jakarta: Inisiasi Press, 2006), cet. 1, 16.

${ }^{22} \mathrm{Http}$ : Islamlib.com/idin dex.php?page=artcle7id=747. Di akses tanggal 19 November 2014.

${ }^{23}$ Abdul Mustaqim, Living Qur'an dalam Litasan Sejarah Studi Al-Qur'an, dalam Metodologi Penelitian Living Qur'an dan Hadis, Syahiron Syamsuddin, 70.

${ }^{24}$ Alfani Daud, Islam dan Masyarakat Banjar (Jakarta: Raja Grafindo Persada, 1997), cet. 1, 281.

${ }^{25}$ Dale F. Eickelman, dkk, Al-Qur'an Sains dan Ilmu Sosial (Yogyakarta: Elsaq Press, 2010), cet. 1, 84.
} 
2. Q.S. Yûnus/10:57

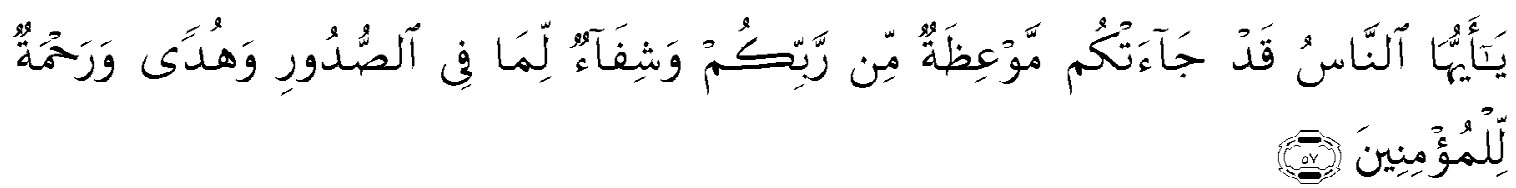

3. Q.S. an-Nahl/16: 69.

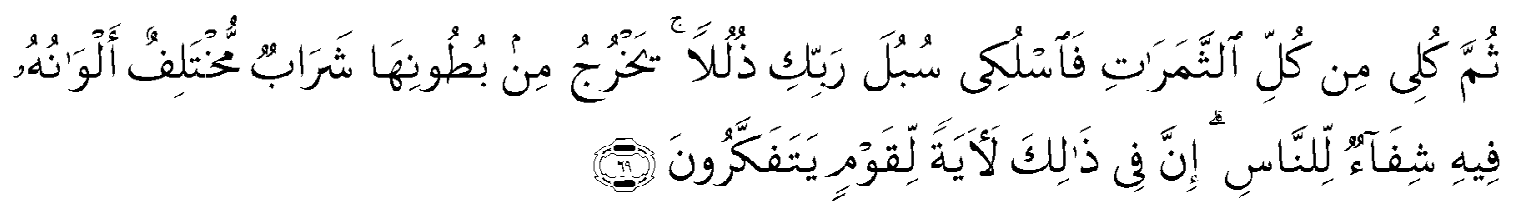

4. Q.S. al-Isrâ'/17: 82.

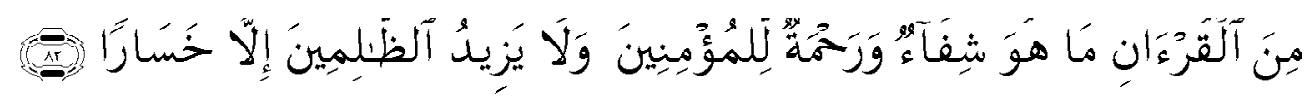

5. Q.S. asy-Syu'arâ'/26: 80.

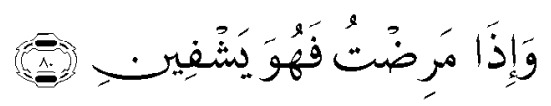

6. Q.S. Fushshilât /41: 44.

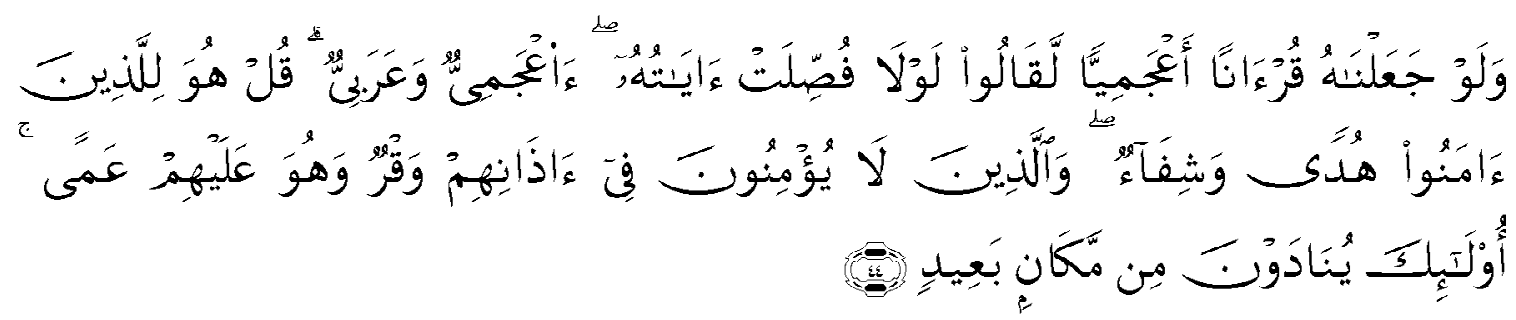

Penjelasan Q.S. At-Taubah/09: 14, sebagaimana yang diungkapkan oleh Rãghib ketika menjelaskan Sadr yang kaitannya dengan Syifấ yaitu memperbaiki seluruh potensi yang berada dalam diri manusia, baik berupa kesenangan (Syahwat), dorongan (Hawa), marah (Gadb) atau disebut juga sebagai akal, hati, ilmu dan sejenisnya. ${ }^{26}$ Pada Q.S. Yûnus/10:57, menegaskan bahwa al-Quran adalah obat bagi apa yang terdapat dalam dada. Penyebutan kata dada yang diartikan dengan hati, menunjukkan bahwa wahyu-wahyu Ilahi itu berfungsi menyembuhkan penyakit-penyakit rohani seperi ragu, dengki, takabbur, dan semacamnya. ${ }^{27}$

Penjelasan dalam Q.S. al-Syu'arâ/26: 80, ayat ini menjelaskan tentang pembicaraan Nabi Ibrahim As. sehubungan dengan sakit dan penyembuhannya.

Penjelasan pada Q.S. al-Isrâ/17: 82, menginformasikan bahwa yang dapat dijadikan sebagai penawar maupun obat bagi orang-orang yang beriman adalah al-Quran. Pada ayat ini tidak menyebutkan secara tegas mengenai penyakit apa yang dapat disembuhkan, melainkan yang tampak jelas adalah bahwa al-Quran itu dapat memberikan manfaat bagi orang-orang yang beriman, bukan kepada orang yang zalim..$^{28}$

\footnotetext{
${ }^{26}$ Aswadi, Konsep Syifa dalam Al-Qur'an..., 91.

${ }^{27}$ M. Quraish Shihab, Tafsir Al-Misbab: Pesan, Kesan dan Keserasian Al-Qur'an (Jakarta: Lentera Hati, 2002), Vol. 5, 438.

${ }^{28}$ Aswadi, Konsep Syifa dalam Al-Qur'an ..., 77.
} 
Ayat dan uraian diatas belum menunjukan secara tegas tentang apa yang dapat dijadikan obat dalam menyembuhkan dalam suatu penyakit. Ayat lainnya masih terkait, ayat-ayat yang mengandung maksud tersebut, telah ditemukan dua jenis Syifấ' yaitu: berupa al-Quran sebagimana terdapat dalam Q.S. al-Isrâ/17: 82, dan berupa madu sebagaimana yang diisyaratkan dalam Q.S. an-Nahl/16: 69.

Ayat Syifâ diatas dengan berbagai tujuannya, berikut makna secara definitif dapat dikatakan bahwa Syifâ adalah segala sesuatu yang diupayakan oleh seseorang dalam penyembuhan manusia dari penyakitnya, sehingga ia menjadi normal, benar keimanan, pemikiran dan akidahnya dalam memperoleh kebahagian di hadapan Allah Swt. dengan demikian dapat dikatakan bahwa Syifâ dalam al-Quran pada hakikatnya adalah penyembuhan dari penyakit. Penyembuhan ini adalah upaya manusia dalam membersihkan dirinya dari berbagai gangguan dan kesulitan lahiriah maupun batiniah. ${ }^{29}$

Sebagai penyembuh bagi orang yang mengamalkannya dan memerlukan penyembuhan. Dengan membaca ayat-ayat yang terdapat dalam al-Quran orang yang membaca akan merasa tenang dan damai. Allah Swt. telah menyatakan bahwa al-Quran sebagai obat dan Rahmat bagi sekalian Mu'min. Dengan al-Quran bisa menyembuhkan penyakit rohani dan jasmani. dan terwujud rasa aman dan keamanan. ${ }^{30}$

Fenomena ini juga terjadi di masyarakat Banjar khususnya di Kecamatan Beruntung Baru Kabupaten Banjar. Mereka mengamalkan al-Quran yang senantiasa dibaca di saat hamil. Tentang ayat-ayat al-Quran yang di baca atau digunakan ketika hamil di antaranya adalah Q.S. al-Fâtihah/ 1: 1-7, Q.S. al-Kahf/18: 1-110, Q.S. Maryam/19: 1-98, Q.S. Luqmân/31: 1-34, Q.S. Yâsîn/36: 1-83, Q.S. Ar-Rahmân/55: 1-78, Q.S. al-Wâqi'ah/56: 1-96, Q.S. ad-Dhuhâ/93: 1-9, Q.S. alIkhlâs/112: 1-4, Q.S. al-Falaq/113: 1-5, Q.S. an-Nâs/114: 1-6.

Ayat disebut di atas yang digunakan ibu hamil dengan berbagai khasiat tersendiri. Dan yang terpenting disini adanya praktek Living Qur'an. Surah dan ayat al-Quran yang di digunakan ibu hamil di Kecamatan Beruntung Baru Kabupaten Banjar yang diamalkan dimasa kehamilan. Dengan berbagai motivasi dan tujuan ibu hamil dalam mengamalkannya.

Setiap orang tua pasti berharap akan mendapatkan anak yang shaleh dan shalehah, mengabdi kepada Allah Swt. dan kepada orang tua. Inilah kekayaan yang akan membahagiakan saat menginjak usia tau nanti. Anak merupakan unsur yang terpenting dalam keluarga. Penerus generasi, pelanjut sejarah, ditangan mereka masa depan umat, kesadaran tentang hal ini sangatlah penting. Dan menjadi tanggung jawab orang tua untuk memberikan pendidikan terbaik bagi anak-anaknya. Allah Swt. telah memperingatkan orang tua merawat anak-anak mereka dengan cara yang benar dan menumpahkan segala perhatian yang mereka butuhkan untuk menjadi orang dewasa yang sehat dan kuat. Pentingnya pendidikan sejak dini serta dampaknya besar bagi anak seperti yang terdapat dalam Hadis:

${ }^{29}$ Aswadi, Konsep Syifa dalam Al-Qur'an ..., 80.

${ }^{30}$ Ahmad Jamhuri Jaharis Nuruddin, Kewajiban Muslim terbadap Al-Qur'an (Jakarta: Madu, t.th.), 62.

${ }^{31}$ Muhammad bin Isma’il abu Abdullah al Bukhari, Al-jami al Musnad al Shahih al Mukhtasar min Umuri Rasullulahi Shallahu alaibi Wa salam: Shabih al-Bukhari (Damsiq: Dar-Thuqu an Najah, tth) Juz. 2, 94. 


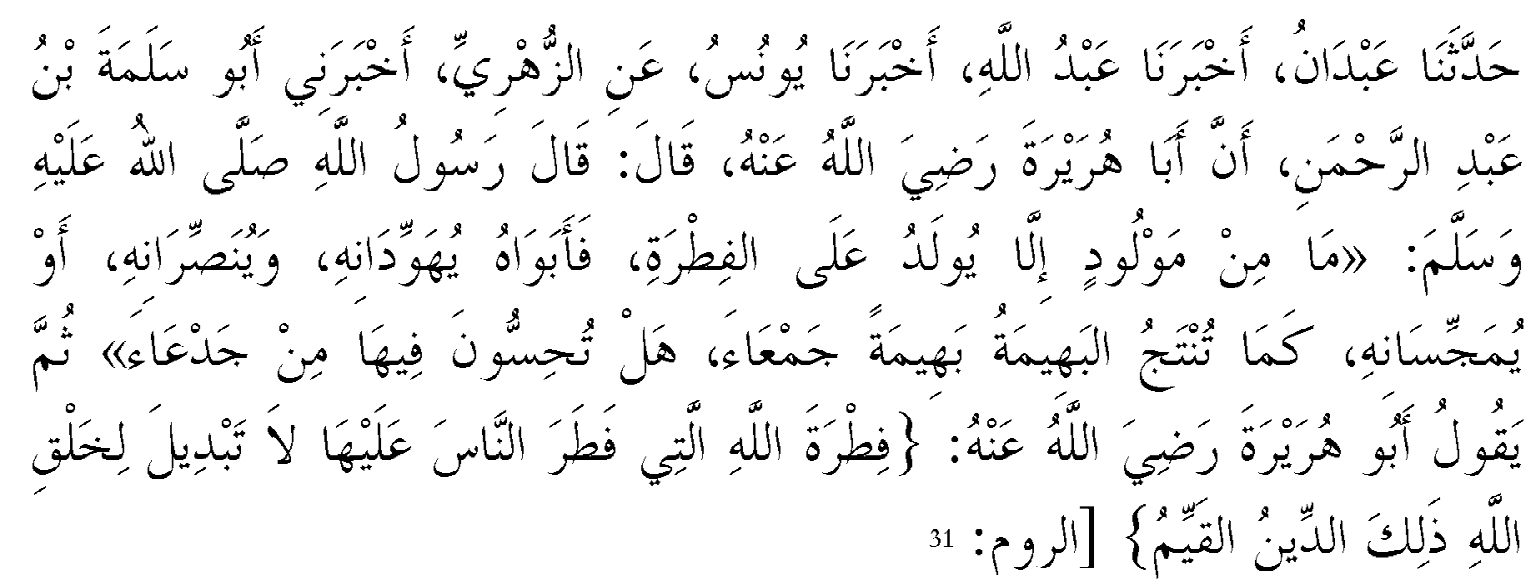

Hadis ini menarik perhatian kalangan pendidik dan ahli jiwa mengenai betapa pentingnya mendidik anak sejak dini. Ibu yang menjadikan mereka Yahudi, Nasrani ataupun Majusi sejak usia dini, tergantung latar belakang agama dan pendidikan si ibu. Pendidikan dini menjadi faktor vital dalam menjadikan anak sebagai seorang Muslim atau Kafir. ${ }^{32}$ Maka hendaknya orang tua menanamkan kebaikan dan meningkatkan kecerdasan anak sudah semenjak anak di dalam kandungan, orang tua kadang lebih mendahulukan anak sehat kuat secara fisik dari pada rohani.

Tidak saja mengenai makanan yang sehat yang dapat memenuhi kebutuhan nutrisi bayi akan tetapi kecerdasan anak dilatih dengan cara beberapa stimulasi yang dapat dilakukan sejak di dalam kandungan. Selama kehamilan bayi di dalam kandungan dapat menyerap latihan ibu yang bertujuan menstimulasi kecerdasannya di kemudian hari. Pada tahap ini, ada beberapa hal yang harus dilakukan sang ibu.

Ibu sebagai guru pertama anak, untuk mendidik buah hatinya semenjak dalam kandungan. Lahirnya anak cerdas dan shaleh-shalehah tidak bisa juga ditentukan secara medis maupun kecukupan gizi saja. Keduanya hanyalah faktor pendukung dan yang tak kalah penting adalah dengan disertai pendidikan agama sejak dalam kandungan. Untuk bisa mendapatkan anak yang baik sehat secara fisik dan mental maka dibutuhkan amalan serta metode pendidikan yang tepat saat dalam kandungan maupun setelah melahirkan.

Praktek menstimulasi anak dalam kandungan telah di kembangkan oleh Nabi Zakaria As. yang telah memberi stimulus pendidikan pralahir pada anak yang dikandung oleh istrinya, sebagaimana diisyaratkan dalam Q.S. Maryam/19:10-11. Di dalamnya dijelaskan bahwa pemberian stimulasi pendidikan pada anak yang dilakukan Nabi Zakaria telah membuahkan hasil yang baik, yakni anak yang memiliki kecerdasan tinggi dalam memahami hukum-hukum Allah. ${ }^{33}$

Demikian diantara keistemewaan al-Quran dan sesungguhnya keistimewaan al-Quran begitu banyak, Allah Swt. mensifatinya dengan firman-Nya, Q.S. Fushshilât/41: 41-42.

${ }^{32}$ Fatimah Umar Nasif, Menggugat Sejarah Perempuan, terj. Burhan Wirasubrata dan Kundun D. Nuryakien (Jakarta: Cendekia Sentra Muslim, 2001), 234.

${ }^{33}$ Felisha Salwanida, Merencanakan Kecerdasan \& Karakter Anak Sejak dalam Kandungan (Jakarta: Katahati, 2010), cet. 1, 44. 


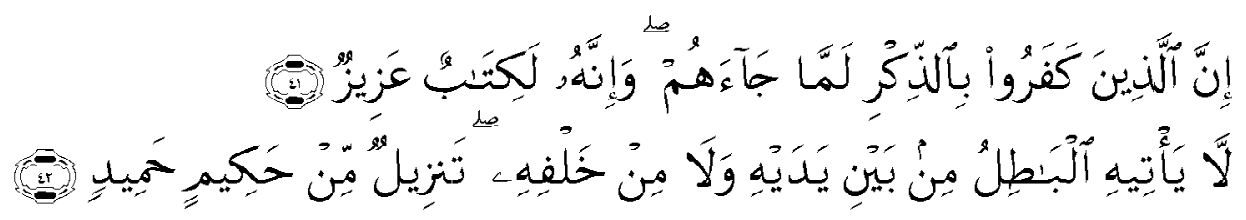

Al-Quran benar-benar dapat memenuhi hajat manusia sepanjang zaman dan sesuai pula dengan tuntutan kemajuan akal manusia yang semakin meningkat. Al-Quran diturunkan dengan sempurna. Semua ayat yang ada didalamnya baik dan memiliki kandungan penting bagi petunjuk manusia. Yang terpenting adalah memahami apa yang dibaca dan dapat mengamalkannya dalam kehidupan sehari-hari.

\section{Hasil}

Hasil dari penelitian di lapangan dengan menggunakan metode yang telah disampaikan di atas, maka diperolehlah surah-surah beserta ayat-ayat al-Quran yang dinyatakan oleh sebagian ibu hamil di Kecamatan Beruntung Baru Kabupaten Banjar, yang di amalkan atau sebagai Living Qur'an. Yang disusun berdasarkan urutan penomoran Surah dalam al-Quran, sebagai berikut:

a. Surah-surah yang di amalkan secara keseluruhan

1. Q.S. al-Fâtihah/1: 1-7.

2. Q.S. al-Kahf/18: 1-110.

3. Q.S. Maryam/19: 1-98.

4. Q.S. Luqmân/31: 1-34.

5. Q.S. Yâsîn/36: 1-83.

6. Q.S. Ar-Rahmân/55: 1-78

7. Q.S. al-Wâqi'ah/56: 1-96.

8. Q.S. ad-Dhuhâ/93: 1-9.

9. Q.S. al-Ikhlâs/112: 1-4.

10. Q.S. al-Falaq/113: 1-5.

11. Q.S. an-Nâs/114: 1-6.

b. Ayat-ayat yang di amalkan

1. Q.S. al-Baqarah/2: 128.

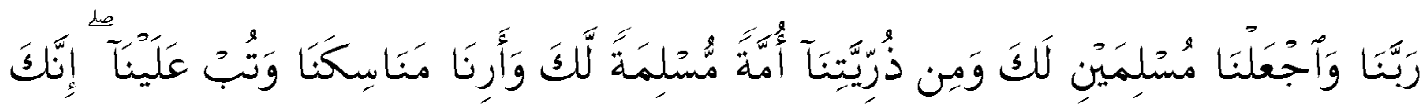

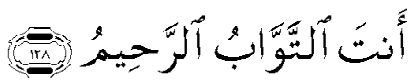

2. Q.S. al-Imrân/3: 8-9 dan 38:

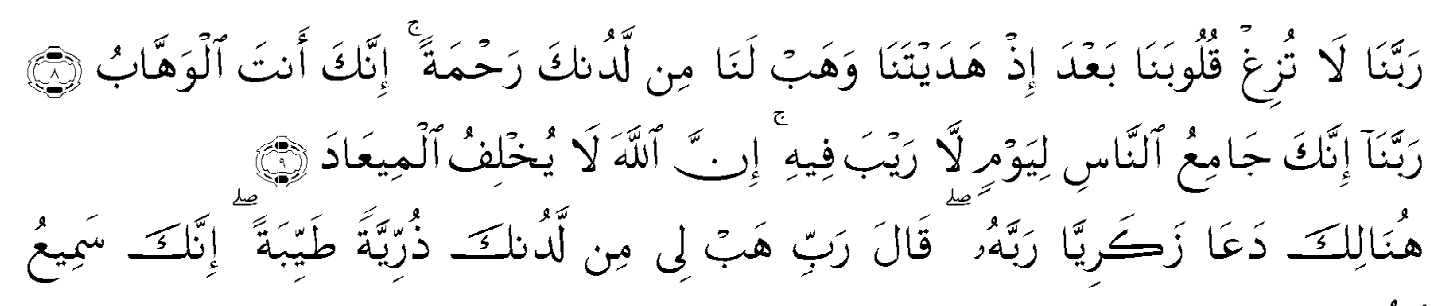


3. Q.S. al-Arâf/07: 54 .

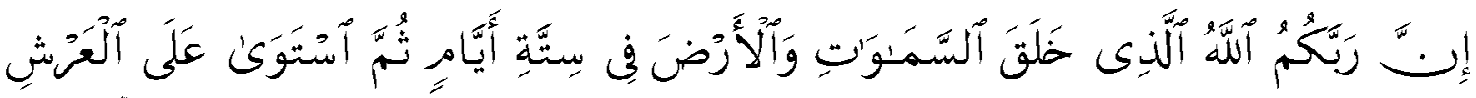

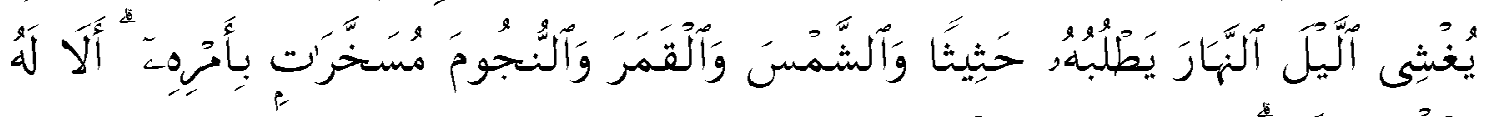

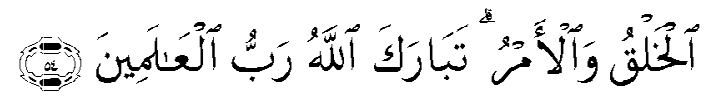

4. Q.S. Yûnus/10: 31.

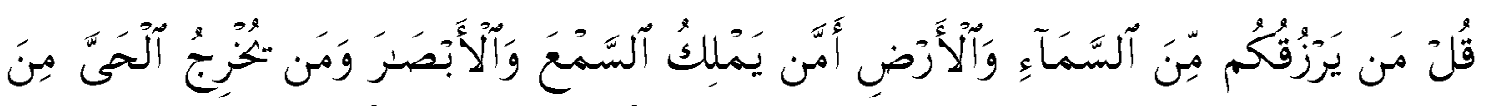

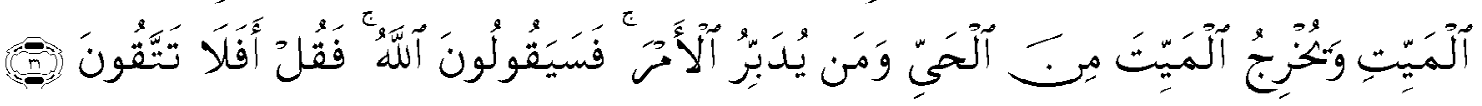

5. Q.S. Yûsuf/12: 4, 31.

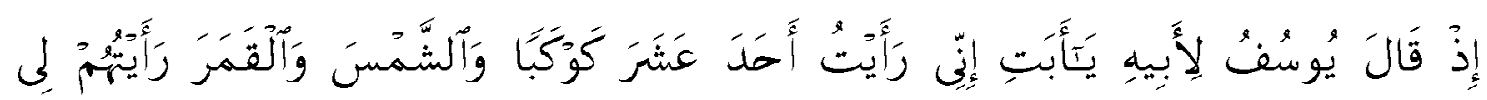

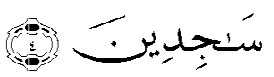

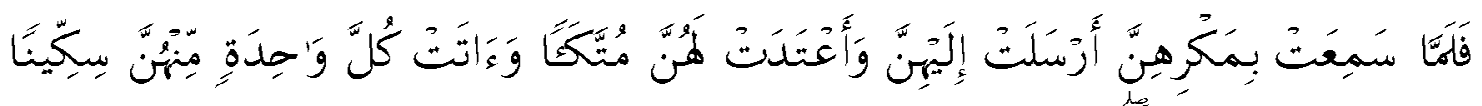

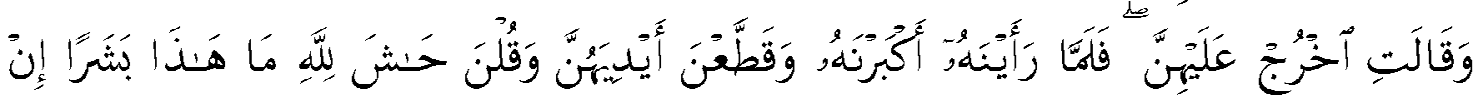

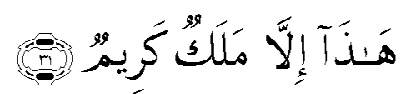

6. Q.S. Ibrâhîm/14: 40

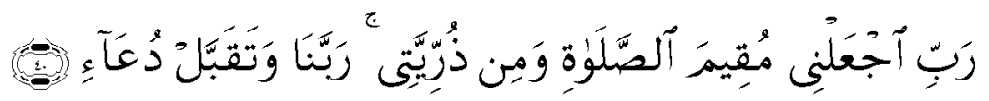

7. Q.S. an-Nahl/16: 78 .

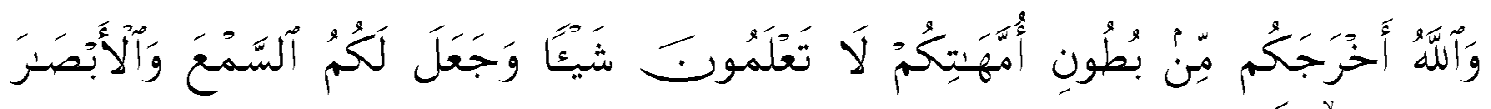

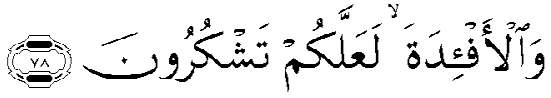

8. Q.S. al-Anbiyâ/21: 87.

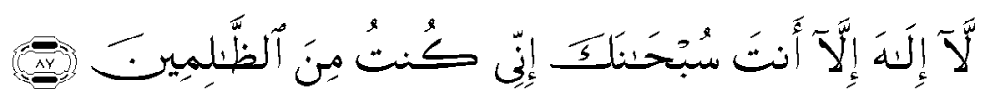

9. Q.S. al-Furqân/25: 74.

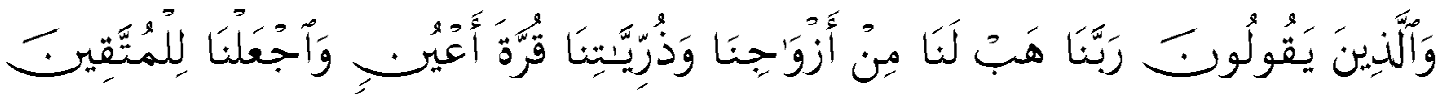

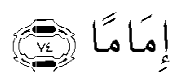


10. Q.S. al-Insyirah/94: 5-6.

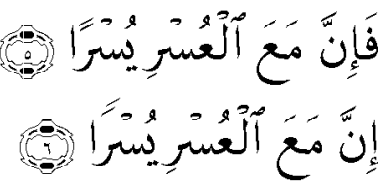

11. Q.S. az-Zalzalah/99: 1-2.

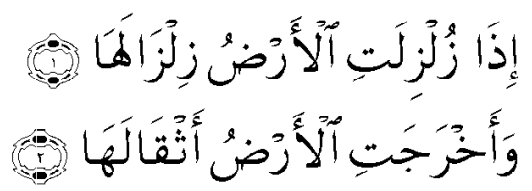

\section{Simpulan}

Kesimpulan Dari hasil interview mendalam terhadap lima belas responden studi living Qur'an terhadap amalan ibu hamil di Kecamatan Beruntung Baru Kabupaten Banjar. Tabel berikut ini disusun berdasarkan surah-surah dan ayat al-Quran yang paling banyak di gunakan.

\begin{tabular}{|c|l|l|l|}
\hline No. & \multicolumn{1}{|c|}{ Surah } & \multicolumn{1}{c|}{ Pengamal } & \multicolumn{1}{c|}{ Responden } \\
\hline 1 & Q.S. Maryam/19. & 13 orang & $\begin{array}{l}\text { I, II, III, VI, VII, VIII, IX, } \\
\text { X, XI, XII, XIII, XV. }\end{array}$ \\
\hline 2 & Q.S. Yusuf/12. & 06 orang & I, VII, VIII, X, XII, XIII. \\
\hline 3 & Q.S. al-Anbiyâ/21: 87. & 5 orang & I, II, VI, X, XII. \\
\hline 4 & Q.S. Yâsîn/36. & 3 orang & I, IV, XII. \\
\hline 5 & Q.S. al-Kahf/18. & 3 orang & XI, XII, XIII. \\
\hline 6 & Q.S. al-Ikhlâs/112. & 3 orang & II, VI, XIV. \\
\hline 7 & Q.S. al-Falaq/113. & 2 orang & V, XIII. \\
\hline 8 & Q.S. an-Nas/114. & 2 orang & V, VIII. \\
\hline 9 & Q.S. ad-Dhuhhâ/93. & 1 orang & II. \\
\hline 10 & Q.S. az-Zalzalah/99. & 1 orang & V. \\
\hline 11 & Q.S. al-Fâtihah/01. & 1 orang & XIV. \\
\hline 12 & Q.S. al Insyirah/94. & 1 orang & XI. \\
\hline
\end{tabular}

Tujuan pelaksanaan pembacaan (pengamalan) al-Quran bertujuan memperoleh "Berkah" dari al-Quran dengan berbagai motifasi yang ditanamkan oleh para ibu hamil untuk membaca al-Quran yang bermanfaat dikemudian hari bagi anak yang dilahirkannya kelak. Motifasi ibuibu ketika hamil membaca (mengamalkan) surah dan ayat al-Quran seperti doa yang terkandung dalam surah dan ayat al-Quran mereka amalkan yaitu:

1) Agar ibu yang mengandungnya selamat dari bahaya yang ditakutinya ketika melahirkan nantinya.

2) Agar mendapatkan anak yang shaleh-shalehah.

3) Doa agar anak taat kepada Allah.

4) Doa agar anak tetap mengerjakan shalat.

5) Doa agar anak terhindar dari kemusyirikan untuk menjaga aqidah dan diberi hidayah kepada anak. 
6) Doa agar di karuniakan anak yang menyejukkan hati ibu bapaknya,

7) Doa mendisiplinkan anak.

8) Doa untuk kebahagian sekeluarga.

Dengan mengamalakan surah dan ayat al-Quran semenjak dalam kandungan ibu juga telah mengajarkan nilai Spritual menanamkan nilai-nilai Islam (Qur'ani) dan pendalaman pengetahuan ke-Islaman kepada anaknya.

\section{DAFTAR PUSTAKA}

Aswadi, Konsep Syifa dalam Al-Qur'an cet. 1. Jakarta: Kementrian Agama RI, 2012.

Yusuf, Muhammad. Pedekatan Sosiologi dalam Penelitian Living Qur'an, dalam Metodologi Penelitian Living Qur'an dan Hadis, Syahiron Syamsuddin, cet. 1. Yogyakarta: TH Press, 2007.

Umar Nasif, Fatimah. Menggugat Sejarah Perempuan, terj. Burhan Wirasubrata dan Kundun D. Nuryakien. Jakarta: Cendekia Sentra Muslim, 2001.

Tim Perumus Fakultas UMJ Jakarta, Al-Islam dan Iptek. Jakarta: PT. Raja Grafindo Persada, 1998.

Shihab, M. Quraish. Tafsir Al-Misbah, Vol. 1 Jakarta: Lentera Hati, 2002.

Salwanida, Felisha. Merencanakan Kecerdasan \& Karakter Anak Sejak dalam Kandungan, cet. 1. Jakarta: Katahati, 2010.

Sako Muhammad, Ahsin. Inseklopedi Kemukjizatan Ilmiah dalam Al-Quran dan Sunnah. cet. 2. Jakarta: Kharisma Ilmu, 2010.

Rahman ghozali, Abdul. Fiqhi Munakahat, cet. 4. Jakarta: Kencana, 2010.

Poerwadarminta, W.J.S. Kamus Umum Bahasa Indonesia, cet. 7. Jakarta: Balai Pustaka, 2010.

Pandi Wirakusumah, Emma. Sehat Cara AL-Qura'an dan Hadis, cet. 1.Jakarta: Hikmah, 2010.

Nuruddin, Ahmad Jamhuri Jaharis. Kewajiban Muslim terhadap Al-Qur'an. Jakarta: Madu, t.th.

Mustaqim, Abdul. Living Qur'an dalam Litasan Sejarah Studi Al-Qur'an, dalam Metodologi Penelitian Living Qur'an dan Hadis, Syahiron Syamsuddin, cet. 1. Yogyakarta: TH Press, 2007.

Mansur, Muhammad dkk. Living Qur'an dalam Litasan Sejarah Studi Al-Qur'an, dalam Metodologi Penelitian Living Qur'an dan Hadis, Syahiron Syamsuddin, cet. 1. Yogyakarta: TH Press, 2007.

M. Echols, John dan Hassan Syadily. Kamus Inggris Indonesia. Surabaya: Usaha Nasional, 1996.

Kholis, Nur. Pengantar Studi Al-Qur'an dan Al-Hadist, cet. 1. Yogjakarta: Teras, 2008.

Kamus Umum Bahasa Indonesia, cet. 1. Jakarta: Pusat Balai Bahasa Indonesia, 2010.

Hadi, Risno. Metodologi Resecrch. Yogyakarta: Aadi Otset, 1994.

F. Eickelman, Dale dkk. Al-Qur'an Sains dan Ilmu Sosial, cet. 1. Yogjakarta: Elsaq Press, 2010.

Esack, Farid. Menghidupkan Al-Qur'an dalam Wacana \& Prilaku, Judul Asli: al-Qur'an a Short Introduction, Penerjemah : Norma Arbi’â Juli Setiawan, cet. 1. Jakarta: Inisiasi Press, 2006.

Daud, Alfani. Islam dan Masyarakat Banjar, cet. 1. Jakarta: Raja Grafindo Persada, 1997. 
Chirzin, Muhammad. Mengungkap Pengalaman Muslim Berinteraksi dengan al-Qur'an, dalam Metodologi Penelitian Living Qur'an dan Hadis. Syahiron Syamsuddin, cet. 1. Yogyakarta: TH Press, 2007.

Al-Bukhâriy, Abû 'Abd Allâh Muhammad ibn Ismâ’îl. Al-Jami al Musnad al Shahih al Mukhtasar min Umuri Rasullulahi Shallahu alaihi Wa salam: Shahîh. al-Bukhârî, Juz. 2. Damsiq: Dar-Thuqu an Najah, tth.

AI, Novaria dan TP Budi. Tips Cerdas Kehamilan, cet. 1. Jakarta: Suka Buku, 2012.

A Partanto, Pius dan M. Dahlan al Barry. Kamus Ilmiah Populer. Surabaya: Arloka, 1994.

Suryadilaga, M. Alfatih. Living Hadis dalam Kerangka Dasar Keilmuan UIN Sunan Kalijaga,Http:/ / ejournal.unp.ac.id/index.php/pnfi/article/download/1516/pdf, (02 November 2014).

Http : Islamlib.com/idin dex.php?page=artcle7id=747. Di akses tanggal 19 November 2014. 